\title{
Abscesso espinhal epidural por disseminação hematogênica: relato de caso
}

\section{Spinal Epidural Abscess by Hematogenous Spread: Case Report}

\author{
Leonardo Cruz Alexandre ${ }^{1}$ Fabrício Martinelli ${ }^{1}$ Rafael Teichmann Medeiros ${ }^{2}$ Giana Flávia Kühn ${ }^{2}$ \\ Joel Machado ${ }^{2}$ Maurício Valentini Tomiello ${ }^{2}$ Rodrigo de Camargo Zan ${ }^{3}$
}

\footnotetext{
${ }^{1}$ Acadêmico de Medicina, Universidade do Sul de Santa Catarina (UNISUL), Tubarão, SC, Brasil

2 Médico Residente, Neurocirurgia, Hospital Nossa Senhora de

Pompéia, Caxias do Sul, RS, Brasil

${ }^{3}$ Neurocirurgião Chefe da Residência de Neurocirurgia, Hospital

Nossa Senhora de Pompéia, Caxias do Sul, RS, Brasil
}

\begin{abstract}
Address for correspondence Leonardo Cruz Alexandre, Rua Presidente Kennedy, 215, Pio Corrêa. Criciúma, SC, Brasil. CEP 88811540 (e-mail: leonardo.cruz.alexandre@gmail.com).
\end{abstract}

\section{Resumo \\ Palavras-Chave \\ - abscesso espinhal epidural \\ - paralisia \\ - disseminação hematogênica}

\section{Abstract \\ Keywords \\ - spinal epidural abscess \\ - paralysis \\ - hematogenous spread}

Abscesso espinhal epidural é uma doença rara de diagnóstico difícil, sendo que o principal fator prognóstico é o diagnóstico breve. A maioria dos pacientes, porém, tem o diagnóstico tardio, quando já existem sintomas neurológicos que podem permanecer após o tratamento. Na maioria dos casos, os sintomas iniciais são dor nas costas, febre e paralisia. O tratamento é feito à base de antibioticoterapia empírica e, caso não haja contraindicação, descompressão e drenagem cirúrgica. Relata-se o caso de uma paciente que sofreu paralisia súbita nos membros inferiores. Inicialmente, havia suspeita de mielite transversa, mas a evolução do caso permitiu o diagnóstico de abscesso espinhal epidural em T6, T7 e T8, causada por disseminação hematogênica de Staphylococcus aureus.

Spinal epidural abscess is a rare and difficult disease to diagnose, and the main prognostic factor is the early diagnosis. Most patients, however, have their diagnosis delayed to when they already have neurological symptoms that may remain after treatment. In most cases, the initial symptoms are back pain, fever and paralysis. Treatment is based on empirical antibiotic therapy and, if there is no contraindication, decompression and surgical drainage. We report the case of a patient who suffered sudden paralysis of the inferior members. Initially suspected as transverse myelitis, the case evolved, allowing the diagnosis of spinal epidural abscess in T6, T7 and T8, caused by hematogenous spread of Staphylococcus aureus. received

March 14, 2015

accepted

August 28, 2015

published online

February 12, 2016
DOI http://dx.doi.org/

10.1055/s-0035-1571208. ISSN 0103-5355.
Copyright $@ 2016$ by Thieme Publicações License terms

Ltda, Rio de Janeiro, Brazil 


\section{Introdução}

Abscesso espinhal epidural é uma infecção rara, porém severa. Requer atenção imediata, pois o principal fator prognóstico é o diagnóstico breve, que leva ao tratamento adequado. ${ }^{1}$ De fato, pacientes com diagnóstico tardio (75\% deles) têm chances 6 vezes maiores de persistirem com sintomas neurológicos, ao contrário daqueles com diagnóstico breve. ${ }^{2}$ Dos pacientes com abscesso, praticamente todos possuem pelo menos um fator de risco, sendo eles: uso de drogas intravenosas, imunocomprometimento, abuso de álcool, procedimento recente na espinha, infecção em outro local, diabetes, sonda vesical por longo período, fratura espinhal recente, insuficiência renal crônica ou câncer. ${ }^{3} \mathrm{~A}$ disseminação pode ser por contiguidade, (um terço dos casos) ou hematogênica (metade dos casos). ${ }^{4}$

No caso apresentado abaixo, houve um foco local de infecção que levou à disseminação hematogênica da bactéria, causando o quadro de abscesso espinhal epidural.

\section{Relato de Caso}

Paciente do sexo feminino, 18 anos, procurou atendimento com queixa de paraplegia súbita ao acordar pela manhã. Depois de solicitada ressonância magnética (RM) de coluna, a paciente foi encaminhada para o serviço de neurocirurgia do Hospital Pompeia, em Caxias do Sul. Associada à paraplegia, exibia incontinência urinária e fecal.

Ao exame neurológico, encontrava-se lúcida e orientada, com pupilas isocóricas e fotorreagentes, e pares cranianos sem alterações. Havia hiperreflexia de membros inferiores, clônus e força grau zero. A sensibilidade estava preservada em todos os dermátomos. Ao exame físico geral, estava em bom estado, com fácies atípica, normotensa, mucosas coradas e hidratadas, afebril e sem linfonodomegalias. Apresentava infecção no hálux direito, decorrente de cantoplastia recente. Negou vacinação, diarreia ou infecção de vias aãreas superiores (IVAS) recentes, bem como patologias reumatológicas.

No mesmo dia, foi realizada punção lombar e rotina de líquor, que se revelou normal. Após o resultado da RM de

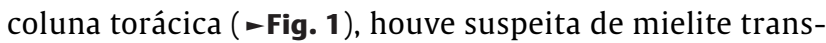
versa, e foi iniciado plano de pulsoterapia com metilprednisolona em bomba de infusão durante 5 dias. No segundo dia, a força do pé direito apresentou melhora (grau II). Após nova RM, ao fim da pulsoterapia, constatou-se possível aumento da lesão extramedular. Programou-se microcirurgia de tumor medular para a realização de biópsia no dia seguinte. 0 material enviado para cultura microbiológica retornou com crescimento de Staphylococcus aureus multissensível; muito provavelmente, consequência do foco infeccioso do hálux direito. A paciente foi tratada com oxacilina em dose máxima por 14 dias, além de ter o foco infeccioso eliminado (-Fig. 2).

Ao fim da antibioticoterapia, a paciente estava deambulando, com força grau IV, e apresentava bom controle esfincteriano. Na alta hospitalar, foi prescrito ciprofloxacino por 75 dias. No acompanhamento ambulatorial, após 3 meses, o quadro neurológico encontrava-se estável.

\section{Discussão}

Em uma metanálise em que foram analisados 915 pacientes com abscesso espinhal epidural, constatou-se que a idade

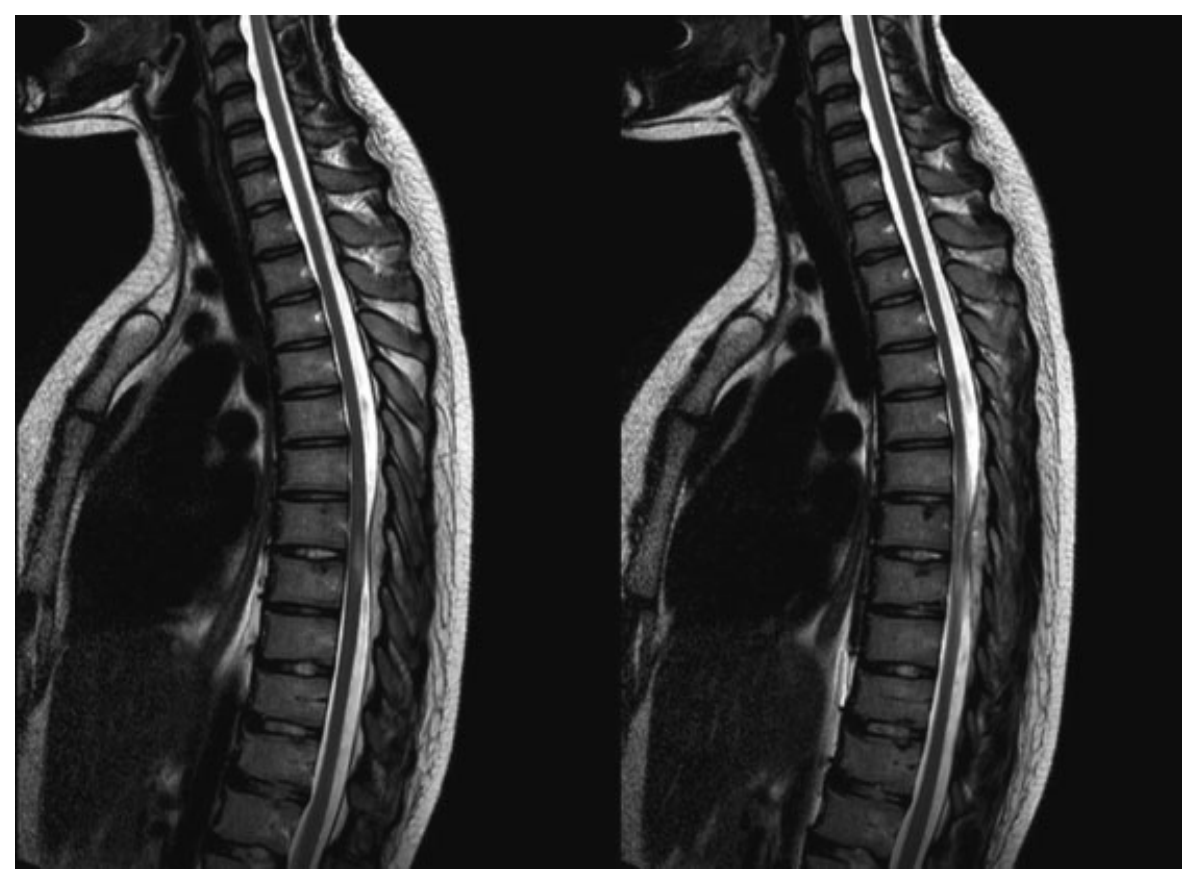

Fig. 1 Ressonância magnética de coluna torácica: formação expansiva de aspecto fusiforme no espaço epidural, ao nível dos corpos vertebrais de T6, T7 e T8, com intensa impregnação pelo meio de contraste. Nota-se também alteração de sinal da medula torácica nesse nível por mielopatia. Os espaços discais apresentam-se preservados. 


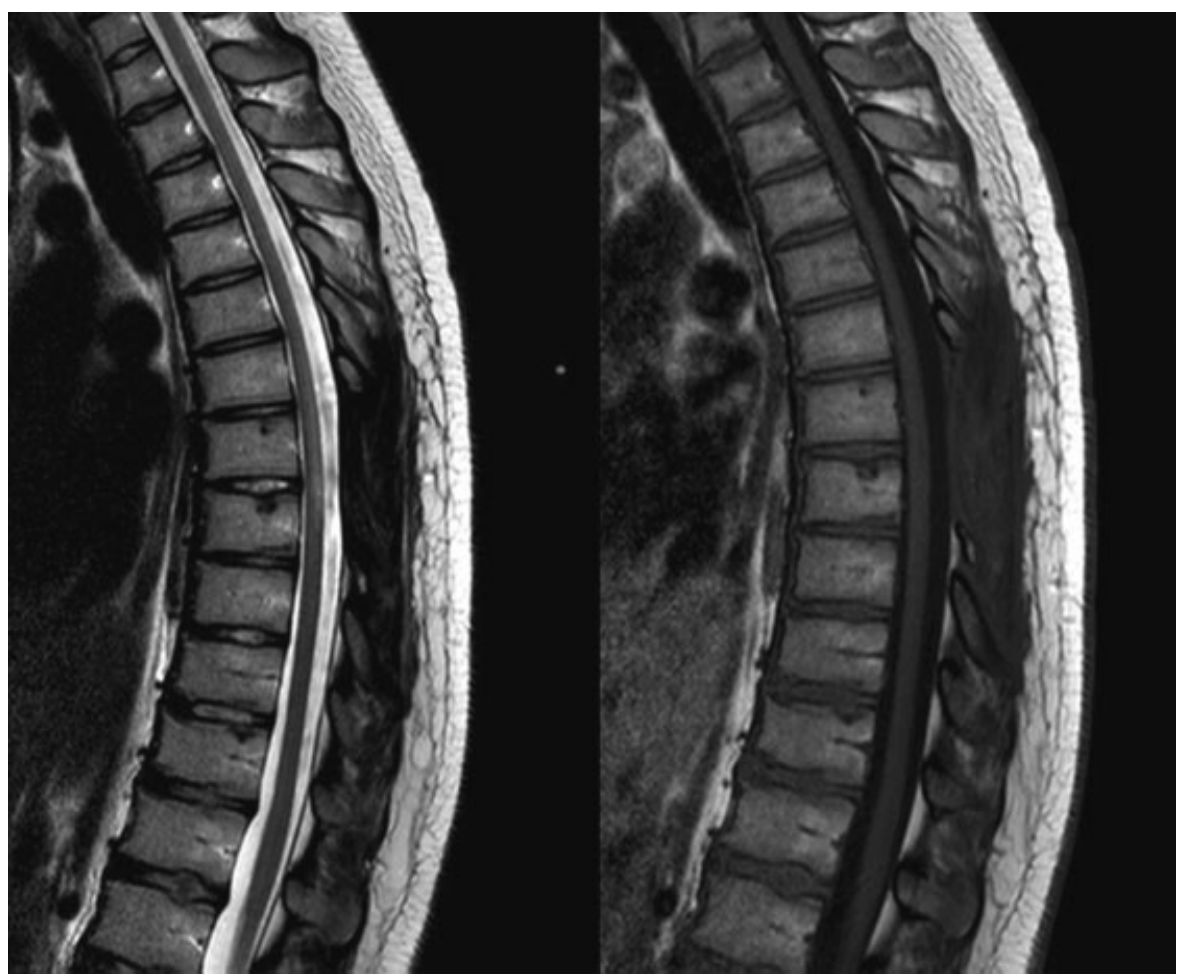

Fig. 2 Ressonância magnética após o tratamento.

mais acometida foi entre 30 e 60 anos, com maior número de homens que de mulheres. A incidência geral ficou em torno de 0,2 a 2 casos a cada 10 mil admissões hospitalares. Os fatores de risco mais comuns foram diabetes melito, trauma, uso de drogas intravenosas e alcoolismo. Abscessos cutâneos e furúnculos foram a causa mais comum de infecção. Em relação aos sintomas, $71 \%$ apresentavam dor nas costas como sintoma inicial, e $66 \%$ apresentavam febre, sendo que apenas $34 \%$ dos pacientes tiveram paralisia. ${ }^{5}$

Uma diretriz para facilitar o diagnóstico foi proposta em 2011, já que a demora deste é o principal fator prognóstico. Davis et al $^{6}$ relatam que $83,6 \%$ dos pacientes tiveram diagnóstico tardio, com déficit motor presente em $81,8 \%$ deles no momento do diagnóstico. A tríade clássica de febre, dor espinhal e déficit neurológico foi observada em apenas $2 \%$ dos casos. Um dado interessante observado no trabalho foi que todos os pacientes com abscesso espinhal epidural apresentavam pelo menos um fator de risco para a doença (sendo a infecção local encontrada em $26 \%$ dos casos). Em relação à diretriz, os primeiros exames laboratoriais propostos foram a velocidade de hemossedimentaão (VHS) e a proteína $\mathrm{C}$ reativa (PCR). O VHS encontrou-se elevado (> $20 \mathrm{~mm} / \mathrm{h}$ ) em 100\% dos casos, contra 33\% sem abscesso; já o PCR encontrou-se elevado $(>1,0)$ em $87 \%$ dos casos com abscesso, contra $50 \%$ sem este. A sensibilidade e a especificidade para a apresentação de pelo menos um fator de risco com o VHS elevado foram de 100 e $67 \%$, respectivamente com e sem abscesso.

Outros resultados podem ser encontrados, como trombocitopenia, leucocitose, e cultura sanguínea positiva, especialmente útil em casos de disseminação hematogênica e uso de drogas intravenosas. ${ }^{7} \mathrm{O}$ principal exame de imagem a ser solicitado é a ressonância magnética, que tem uma sensibilidade em torno de $91 \%$ para diagnóstico do abscesso espinhal epidural, sendo útil também na avaliação pré-operatória. ${ }^{1}$

O tratamento do abscesso espinhal epidural é bem estabelecido. O uso de antibióticos empíricos deve ser iniciado assim que for feito o diagnóstico, podendo ser usada cefalosporina de terceira geração com vancomicina intravenosa e rifampicina via oral. ${ }^{1} \mathrm{O}$ uso da antibioticoterapia deve ser guiado pelos achados de cultura sanguínea, sendo que o patógeno mais frequentemente envolvido no quadro é o Staphylococcus aureus. ${ }^{7}$ Se não houver contraindicação, o paciente deve ser submetido a descompressão e drenagem cirúrgica. ${ }^{8}$

Em relação ao prognóstico, o estágio pré-operatório de Heusner $^{9}$ ( - Tabela 1 ) é o fator preditor mais importante de uma boa recuperação neurológica pós-operatória ${ }^{1,4}$, porém, nem sempre se observa uma linearidade no seguimento dos

Tabela 1 Estágios clínicos do abscesso espinhal epidural

\begin{tabular}{|l|l|}
\hline Estágio & Sinais clínicos \\
\hline I & Dor nas costas, febre e sensibilidade na coluna \\
\hline II & Rigidez nucal, hiper-reflexia, dor radicular \\
\hline III & $\begin{array}{l}\text { Alterações sensoriais, fraqueza motora, } \\
\text { incontinência intestinal ou urinária }\end{array}$ \\
\hline IV & Paralisia \\
\hline
\end{tabular}


estágios, podendo o paciente já se apresentar à emergência no estágio IV.

\section{Referências}

1 Sendi P, Bregenzer T, Zimmerli W. Spinal epidural abscess in clinical practice. QJM 2008;101(1):1-12

2 Davis DP, Wold RM, Patel RJ, et al. The clinical presentation and impact of diagnostic delays on emergency department patients with spinal epidural abscess. J Emerg Med 2004;26(3): 285-291

3 Recinos PF, Pradilla G, Crompton P. Thai Q-A, Rigamonti D. Spinal epidural abscess: diagnosis and treatment. Operat Tech Neurosurgy $2004 ; 7: 188-192$
4 Darouiche RO. Spinal epidural abscess. N Engl J Med 2006;355(19):2012-2020

5 Reihsaus E, Waldbaur H, Seeling W. Spinal epidural abscess: a meta-analysis of 915 patients. Neurosurg Rev 2000;23(4):175-204, discussion 205

6 Davis DP, Salazar A, Chan TC, Vilke GM. Prospective evaluation of a clinical decision guideline to diagnose spinal epidural abscess in patients who present to the emergency department with spine pain. J Neurosurg Spine 2011;14(6):765-770

7 Grewal S, Hocking G, Wildsmith JAW. Epidural abscesses. Br J Anaesth 2006;96(3):292-302

8 Haas BM, Yu YH, Kim J. Morbidity and Mortality Reports: Delay in Diagnosis of Spinal Epidural Abscess. Neurol Bull 2011;3:18-24

9 Heusner AP. Nontuberculous spinal epidural infections. N Engl J Med 1948;239(23):845-854 